\title{
Metaphysics and Representation: Derrida's Views on the Truth in Painting
}

Chung Chin-Yi

National University of Singapore

\begin{abstract}
This paper discusses Derrida's deconstruction of both representational and postrepresentational thinking, in pointing out that they both assume a realist or representational paradigm as its assumption. It examines Rosemary Hawker's contention that Derrida's argument is one fundamentally concerned about the inseparability of idiom and content, and argues that indeed this was an accurate reading; Heidegger and Shapiro's fallacy as interpreted by Derrida is precisely the trap of metaphysical and representational thinking in assuming that content is separable from form. It also examines Marcellini and Haber's arguments that Derrida's arguments are about the failure of the representational paradigm of thinking as there is always a surplus and excess of meaning because each rendering differs from its origin. Finally it finds out that there is no such thing as pure representation as art always renders its object with a difference, or differance.
\end{abstract}

[Keywords: Truth, Heidegger, Shapiro, Representation, Deconstruction, Marcellini ]

In The Truth in Painting, Heidegger's attempt to 'go beneath or behind the metaphysical determination of truth (Derrida, 1987:30) remains committed to the anthropological project. While Heidegger sought to break away from representation, Heidegger remained humanist and anthropomorphic. Derrida illustrates this through examining the Heidegger-Shapiro correspondence about Van Gogh's shoes to explore this theme. Derrida contrasts Shapiro, the city dweller, with Heidegger, the champion of peasant ideology, and illustrates the paradox of the controversy- that both contenders share more common ground that they believe - the trap of representational thinking. Rather than defend either Heidegger or Shapiro, he exposes the 'tacit institution' in their correspondence. (Derrida, 1987:281) The shared institutional commitment concerns a representational mode of epistemology. Derrida thinks Shapiro is trapped in representational thinking in seeking the identity of the person who dons the shoes, while Heidegger is trapped more subtly.

In disputing the identity of the person who dons the shoes, Derrida alleges that both Shapiro and Heidegger have assumed the traditional paradigm of painting - realism and representation. Both assume that the shoes must belong to a real correspondent person - a peasant or Van Gogh, which the painting merely depicts or represents. While Shapiro takes a strictly realist approach to the picture in insisting it is Van Gogh's depiction of his own city shoes, Heidegger too does not escape the trap of representation in assuming that the shoes' status as equipment must be disclosed by the painting, which presupposes the Platonic idea of the naked thing stripped of use value, prior to the painting which the painting must henceforth disclose or unconceal as equipment or of utility, as Derrida calls it, a being-product. This artistic presencing of the authentic mode of the shoes as equipment and utility is but another form of representational thinking that Heidegger fails to escape, although Heidegger proclaims his work a form of

Rupkatha Journal on Interdisciplinary Studies in Humanities

Volume 2, Number 1, Special Issue, Visual Arts

URL of the Issue: http://rupkatha.com/rupkathav2n1.php

PDF URL of the article: http://rupkatha.com/V2/n1/Derridatruthinpainting.pdf

(c) www.rupkatha.com 
post-metaphysical and post-representational thinking. The ghost of Plato and his concept of the naked thing haunts Heidegger's conception of aletheia.

Derrida argues that Heidegger has not escaped a metaphysical concept of the thing in conceiving in terms of a matter-form complex. Derrida further notes that Heidegger is more interested in the thing as a metaphysical object to be unconcealed, than as an artwork- that form and matter - is renamed the concealed and unconcealed through Heidegger's treatise on the artwork, but presumes a similar metaphysical and ontological structure. Hence Heidegger repeats metaphysics rather than deviates from it.

Derrida thus contends that Heidegger assumes the Platonic conception of form and matter by conceiving of the thing divested of use value, a naked thing stripped of its equipmentality, and the artwork that unconceals its use value or equipmentality for us. Derrida argues that the 'naked' thing is an import from Plato and that the remainder is not a naked thing as the object is nothing outside its mediation- the signified is nothing outside the signifier and the transcendental is nothing outside the empirical. Derrida argues that Heidegger's realm of the 'concealed' naked thing stripped of equipmentality and use value is a metaphysical abstraction that has imprints of Platonic metaphysical thought in it. Thus Heidegger, for all his post-metaphysical and post-representational rhethoric, repeats metaphysics rather than managing to escape it with his reconfiguration or truth as aletheia. Derrida is not however critical of this repetition of metaphysics, he only contends that it does not set out what Heidegger sought to do- which was to destroy and overcome metaphysics. Derrida wishes to point out the aporias of this destruction which paradoxically becomes repetition rather than negation.

Derrida argues that both Shapiro's realism and Heidegger's aletheia are committed to a form of representative epistemology which involves detachment of the object from its context and re-attaching it to another function or identity, be it a person in the form of Van Gogh or a function as being-product and utility. Representation, in the form of referential signification, is thus implicit in both Shapiro's realism and Heidegger's aletheia.

Derrida refers to the logic of representation as the logic of the cut or decontextualization. This logic of decontextualization or the logic of the cut leads to opposition as the object is made to refer to that which is entirely other. Derrida argues that this logic of opposition or decontextualization, or strict reference, sublates differance. Derrida points out to the aporia of such an opposition - it is simultaneously stricturation and destricturation as it removes the object from its context to refer it to a meaning wholly other, be it in terms of identity of a person or function of utility in terms of being product. It thus frees, while binding simultaneously, however this movement suppresses and sublates differance as it binds the object to the meaning which is wholly other rather than examining the play between object and referent, which is an indeterminable space rather than the strict determinate space of representation as Heidegger and Shapiro would have it.

In the above passage Derrida seems to argue that re-attachment involves a certain violence in putting uselessness to utility, thus removing its surplus value and subjecting it entirely to utility. In giving itself fully to utility and remarking it entirely as useful, the differance, surplus and indeterminacy of object is erased by lending itself fully to representation as something useful, or equipment. Derrida thus argues that post-representational thought, or aletheia, does not 
escape representational violence as it designates uselessness and utility as a metaphysical and ontological duality that reinscribes aletheia in representation and metaphysics. Heidegger's thought thus does not escape the trap of representational thinking and indeed re-inscribes its metaphysical structure and repeats it in every sense.

Derrida thus further argues that Heidegger, for all his post-representational rhetoric, has assumed the fundamental metaphysical concept of the thing which bears imprints of Plato in its matter-form division. Derrida also argues that Heidegger's aletheia divides representation into 'being product' or thing 2, and pre-disclosed thing naked of equipmental function, or thing I, and this falls into the trap of repeating the fundamental representational logic of thing and perception or signified and signifier, although he claims to have eluded in aletheia by renaming it pre-disclosure and disclosed being-product. Heidegger thus assumes the ontological structure and vocabulary of representational thinking and metaphysics by betraying a dual ontological structure to his postmetaphysics, dividing it into pre-disclosure and being-product. Hence, Heidegger's post-representational thought is not subversion but repetition and paradoxically affirmation of metaphysics and representational thinking.

Derrida contends to conceive of the naked thing, prior to disclosure, translates into an absurdity as signifier is not separable from signified, meaning is irrevocably mediated, the shoes are only disclosed to us as being-product and not as a naked thing stripped of equipmentality. This is because presupposing the naked thing repeats the ontological structure of metaphysics by dividing perception into pre-disclosure and post-disclosure, hence betraying a dual ontological structure that resembles metaphysics and representational thinking. We know of no naked thing as an abstraction apart from its mediation as equipment, Derrida argues that abstracting the naked thing assumes Plato's matter-form division and hence repeats metaphysics. There is thus no division between disclosed thing, and its remainder, the naked thing; as what we encounter is the mediation of the transcendental and the empirical in encountering the pair of shoes as useful without conceiving it as an abstraction that exists prior to representation. Heidegger by abstracting the naked thing thus repeats the ontological structure of representational thinking, thus paradoxically affirming representational thinking rather than deviating from it with his notion of aletheia. from its idiom:

Rosemary Hawker argues that Derrida thinks that painting is inseparable

Idiom and truth are for Derrida found to coalesce in a letter written by Cézanne, which include the statement, "I owe you the truth in painting and I will tell it to you." (Derrida, 1987:2) Derrida seizes on Cézanne's promise as both a highly idiomatic statement and a powerful model of idiom. This short sentence is able to refer simultaneously, and in a manner that escapes adequate translation, to three relations of truth and painting: first, to Cézanne's knowledge of the truth of the medium; second, to the truth of the world as rendered in painting; and, third, to the truth about painting as told through language. In turning to Cézanne's statement, the idiom in painting, with which Derrida began, has now become the truth in painting. Here truth is both the problem of representation more broadly and specifically the problem of representing the medium of painting, or rather representing the medium of painting in writing. Derrida's final configuration of these paired terms, "I am interested in the idiom of truth in painting," completes 
the equation, joining idiom, truth, and painting, but only insofar as it makes clear the folly of attempting to fasten on the idiomatic, much less to reproduce it. Derrida writes:

One is always tempted by this faith in idiom: it supposedly says only one thing, properly speaking, and says it only in linking form and meaning too strictly to lend itself to translation. But if the idiom were this, were it what it is thought it must be, it would not be that, but it would lose all strength and would not make a language. (Derrida, 1987:7)

Here Derrida identifies the paradox of idiom. We know what idiom is meant to be, we understand its functioning in language in the broadest sense. Yet when we try to extract an instance of the idiomatic for contemplation we can be sure that what we have in our sights is the appearance of a form far too nuanced to be isolated. When we use idiomatic language, we do so unselfconsciously; to become conscious of our use of idiom is to have the essential feature of that idiomatic usage slip away from us. (Hawker: 2002)

Hence as we have been discussing in this paper, painting according to Derrida is inseparable from its idiom. We have been discussing this aspect of painting in this paper as the inseparability of the transcendental and empirical, painting is not separable from its representation as mode; painting is only realized through its mode of representation. While we have previously discussed how Heidegger and Shapiro assume the trap of representational thinking in assuming realism and aletheia as a form of disclosure, Hawker here suggests that Derrida's intervention was to imply that painting is not divisible from its mode or idiom, indeed we have seen that Heidegger and Shapiro's attempts to abstract a metaphysical object as the painter or the being product of the shoes' equipmentality only sets up a false Platonic dichotomy between object and its representation, while Hawker argues that Derrida would affirm that idiom is fundamental to rendering the object, the object knows no realization outside its idiom. As Hawker interprets Derrida, and as I would affirm, Derrida highlights that representation is mediation, content is inseparable from its mode of production, this is what Derrida elsewhere calls iterability, or repetition with a difference. Hawker thus suggests painting is nothing outside its rendering or representation, as content is inseparable from idiom, and this is an argument I would agree with and affirm as I have demonstrated in this paper that the fallacy of Heidegger and Shapiro according to Derrida is the trap of representational thinking in assuming form and content are separate, while Derrida would argue that form and content are related in a dynamic relation of iterability and difference. Content knows no instantiation outside its mode, painting is not divisible into subject and object, these are one and the same. Painting is nothing outside its idiom; it is not separable from idiom, but rendered and mediated through its idiom.

John Haber argues that Derrida anticipated issues of representational thinking and its aporia, in The Truth in Painting. As Haber argues, Derrida noted how "rendering" (in both French and English) means both returning to its owner and representing. According to Haber, in the historian's appeal to the facts, Derrida too often detects recourse to a human stand-in for a painting's meanings. The painting acts suspiciously as a "natural" home for the elusive objects that the painter has so disconcertingly strewn about. The shoes may make a pair, and they may belong to Van Gogh, but the painting does not say. Vincent Van Gogh does not reveal the owner of the shoes whose life his painterly gestures may seem to uncover. Haber shows that Derrida cites a letter of Cézanne that 
promises la verité en peinture-to paint truthfully, or maybe to paint the truth, or to speak truthfully about his art, or to paint in fidelity to the medium. In this, Haber argues that Derrida sees the painter's dedication to opposing truths. According to Haber, meaning, communication, and historical context threaten to collide. So too do the difficult promises that these unleash. Haber states that a promise, Derrida notes, is what a philosopher, J. L. Austin, had called a performative-a statement that does something rather than pronounces fact. Haber argues that every painting wishes to be an act much like the Arnolfinis' wedding vow, a promise of certain meaning within a fixed historical frame that no art can ever have. A work of art resembles a game or a hypothesis. Haber states that for an example, Derrida looks at Meyer Schapiro, a defender of modern art who was writing about van Gogh's painting of two shoes. Schapiro was criticizing a sentimental essay from Martin Heidegger., someone else with a past tied up with Nazi Germany. According to Haber, Derrida thinks the art historian used facts rigidly to settle scores. Derrida says that art historians make a game out of restoring a painting to its owner-which might be the painter, the viewer, or the subject. Haber wonders if entrapment between truths and between fictions is inevitable, perhaps it is the most fruitful place to be. Haber suggests there is no such thing as pure witness or representation. There is no one true witness to a painting's event. Haber wonders if it is worthwhile to search for witnesses. According to Haber, if a painting is a reconstruction, its artist a visionary, its images a turning back of vision, and all its witnesses a fiction, it attests to the human need to remember. Haber argues that like a photo album or a maiden name, it does not recover the past, no more than it can put the past at a safe distance. What Haber lends to the discussion of the Truth in Painting is the inadequacy of representation and the failure of the artist representing art as a true or pure witness. Derrida would concur in The Truth in Painting that the representational paradigm is a failed paradigm, because each representation differs from the original and its meaning always exceeds the origin through the relay of differance, the gap between the painting and its object. I would concur with Haber that the representational paradigm of painting seems inadequate according to Derrida, because Derrida would argue that each rendering separates the image from its origin in surplus and differance of meaning. Elsewhere, Derrida argues that meaning is relayed only through the passage of differance, each empirical instantiation of an origin has to differ from it spatially and temporally, and hence become altered in its reinscription as repetition with a difference. Each representation supplants presence. Each reproduction is an iterated form, a separation and differing from the original mark which knows no instantiation outside this structure of repetition. Rendering would always thus fail, because each rendition differs from the original as a trace, or imperfect rendition of the origin, if this indeed exists; as Derrida argues there is nothing outside the text, meaning is irrevocable mediated. As argued earlier, content and idiom are inseparable. They do not exist outside the fundamental structure of mediation that relate each other in a dynamic relation of differance.

Anthony Marcellini argues that in The Truth in Painting, Derrida deconstructs an argument between Martin Heidegger and Meyer Shapiro concerning the origin of a ghost haunting a pair of shoes in a Van Gogh painting. According to Marcellini, Derrida analyzes both Heidegger's position-who believes that the shoes are those of an unnamed peasant-and Mayer Shapiro's-who believes that the shoes belong to the artist Van Gogh. Marcellini 
argues that despite both thinkers very thorough arguments; in the end Derrida resolves that neither Shapiro nor Heidegger are right, because there is really no way to know to whom the shoes belong. Marcellini argues that everything is a presumption of truth. "nothing proves or can prove that 'they are the shoes of the artist'". Derrida says. "Each time you read 'they are clearly...,' 'this is clearly...,' 'are evidently...,' it does not signify that it is clear or evident, very much the contrary, but that it is necessary to deny the intrinsic obscurity of the thing, its essential crypt, and that it's necessary to make us believe that it is clear, quite simply because the proof will always be lacking" (1), he says.

Marcellini argues that to close down individual interpretation, by claiming that the shoes can only be read in one way, seems to Derrida to be entirely against the purpose of the arts. Making them specific and prescribed rather than interpretive. According to Marcellini, Derrida recounts the disenchantment he feels following these philosophers words. "One follows step by step the moves of a 'great thinker,' as he returns to the origin of the work of art and of truth, traversing the whole history of the West and then suddenly, at a bend in a corridor, here we are on a guided tour, as schoolchildren or tourists." (2) According to Marcellini, the thinker has ceased to be a thinker for Derrida and is now simply dictating his own presumptions as fact, like the tour guide of the museum. Marcellini states that this entails only one answer, and that audience becomes a blind follower of the guide under this model.

Marcellini recounts a story told by his professor, Joseph Tanke, about a boy who is harshly silenced and rebuked by a museum tour guide when he responds to her question what might have influenced the visual form of a certain Jasper Johns painting, that perhaps it was the floor of the museum, which looks very similar to the painting. According to Marcellini, here the boy is as right about Johns as Heidegger and Shapiro are about Van Gogh. Marcellini argues that there is no way of knowing what Van Gogh or Johns intended, which closes interpretation. Marcellini eventually affirms that the truth of art is the boy, the museum guide, Shapiro and Heidegger all agreeing that there are multiple truths.

Hence, Marcellini brings to the discussion of The Truth in Painting the idea that the correspondence theory of truth- or that subject correlates to object, fails in art because aesthetics is perspectivism and subjectivity rather than representation. As Marcellini argues, and I would concur about Derrida, meaning always exceeds its origin by being subject to interpretation. Marcellini hence confirms what I have been arguing in this essay, that Derrida argues that the representational mode of thinking for aesthetics is a failed paradigm, because there is nothing outside the text, representation assumes a correlation between the signifier and signified, while Marcellini would argue, and I would affirm, that Derrida argues for a surplus and excess of meaning that exceeds its origin. Heidegger and Shapiro thus operate by the fallacy of the realist paradigm in assuming rendering is a theory of correspondence or an objective reality, where Derrida demonstrates that art always exceeds its origin and differs from the original as differance. As argued with Haber, the representational mode of painting is founded upon failed assumptions because representation is always excess and surplus, differing from the original across the passage of differance and iterability. Representation only retrospectively produces the original because painting is nothing outside its rendering, content is inseparable from idiom.

In terms of style, Truth in Painting is written in a highly elliptical form in order to capture the fact that representation never fully renders its meaning, and 
thus Derrida's deconstruction of both representational realism and postrepresentational aletheia shows that there will always be a surplus of meaning, an excess, as well as its caesuras and silences and gaps between meaning, that will render fully accurate representation inadequate. Derrida, through formal elements such as breaks, ellipsis, and punctuation, demonstrates that no rendering in painting is ever adequate and there is always a surplus of meaning, or differance. Derrida demonstrates through these formal aspects of representation with his writing such as the use of ellipsis and punctuation that pure representation that correlates to a transcendental signified, be it a referent or utility, does not quite happen as there is always a surplus and excess of meaning, or differance.

\section{Bibliography:}

1. Derrida, Jacques. The Truth in Painting. Trans Geoff Bennington. Chicago: CUP, 1987.

2. Hawker, Rosemary "The Idiom in Photography as the Truth in Painting", South Atlantic Quarterly. Volume 101, Number 3, Summer 2002

3. Haber, John. Portraits of a Marriage. http://www. haberarts.com/trueart.htm

4. Marcellini, Anthony. Visions of Ghosts on the Immutable. http://blog.anthonymarcellini.info/tag/derrida/

Chung Chin-Yi is doctoral candidate at the National University of Singapore. Email: enigma719@hotmail.com 